\title{
Anticancer activity of new depsipeptide compound isolated from an endophytic fungus
}

\author{
Shilpa Amit Verekar ${ }^{1}$, Prabhu Dutt Mishra ${ }^{1}$, Eyyammadichiyil Sankaranarayanan Sreekumar ${ }^{1}$, \\ Sunil Kumar Deshmukh ${ }^{1}$, Heinz-Herbert Fiebig ${ }^{2}$, Gerhard Kelter ${ }^{2}$ and Armin Maier ${ }^{2}$ \\ A novel depsipeptide (PM181110) was purified from an endophytic fungus Phomopsis glabrae isolated from the leaves of \\ Pongamia pinnata (family Fabaceae). The chemical structure of PM181110 was elucidated using physiochemical properties, \\ 2D NMR and other spectroscopic methods. PM181110 is very close in structure to FE399. The compound exhibited in vitro \\ anticancer activity against 40 human cancer cell lines with a mean $\mathrm{IC}_{50}$ value of $0.089 \mu \mathrm{m}$ and ex vivo efficacy towards 24 \\ human tumor xenografts (mean $\mathrm{IC}_{50}=0.245 \mu \mathrm{m}$ ).
}

The Journal of Antibiotics (2014) 67, 697-701; doi:10.1038/ja.2014.58; published online 14 May 2014

\section{INTRODUCTION}

Endophytes have been proven to produce bioactive compounds and it is interesting that occasionally they yield those compounds, which are known to be produced by their host. Some anticancer endophytic secondary metabolites are, camptothecin from Entrophosphora infrequens, which is an endophytic fungus from plant bark of Nothapodytes foetida, ${ }^{1}$ vinca alkaloid vincristine isolated from Fusarium oxysporum, which is an endophyte to plant Catharanthus roseus. ${ }^{2}$ An alkaloid chaetoglobosin has been isolated from endophytic fungus Chaetomium globosum IFB-E019 from plant Imperata cylindrica. ${ }^{3}$ There is a report that taxol being produced by Northwest Pacific yew endophyte. ${ }^{4}$ Other anticancer compounds from fungal endophytes include brefeldine, ergoflavin, cytochalasin, depsipeptides and many more. ${ }^{5}$ With our continuing efforts to develop anticancer drugs from natural resources, we discovered a new depsipeptide anticancer compound from Phomopsis glabrae an endophytic fungus. The purification, characterization and biological property of the compound PM181110 are described in this article.

\section{MATERIALS AND METHODS}

General experimental procedures

All the solvents used for extraction were of Laboratory Reagent grade, whereas HPLC grade solvents were used for analytical and preparative HPLC. Purity of the compound was established by analytical HPLC on Shimadzu LC 2010HT using Lichrospher RP-18 $(125 \mathrm{~mm} \times 4.6 \mathrm{~mm}), 5 \mu \mathrm{m}$ column using acetonitrile and water as mobile phase. Normal phase column chromatography was performed on Silica gel (60-120 mesh) and TLC on Silica gel60 F254 $(20 \times 20 \mathrm{~cm})$ aluminum sheets from Merck, Darmstadt, Germany.

The IR spectrum was recorded on Perkin Elmer (Shelton, CT, USA) FT-IR spectrometer using $\mathrm{KBr}$ disc. The compound was analyzed for LC-ESI HRMS on Micro QTOF from Bruker daltonics. The NMR spectra were recorded on Bruker Avance at $500 \mathrm{MHz}$ and $75 \mathrm{MHz}$ for ${ }^{1} \mathrm{H}$ and ${ }^{13} \mathrm{C}$, respectively.
DMDO-d6 was used as solvent for NMR experiments and chemical shifts were referenced the solvent peaks 2.50 p.p.m. $\left({ }^{1} \mathrm{H}\right)$ and 39.5 p.p.m. $\left({ }^{13} \mathrm{C}\right)$. The UV spectrum was extracted from HPLC-photodiode array analysis of compound using solvent system in acetonitrile and water.

Isolation and cultivation of the fungus

The culture PM0509732 was isolated as endophytic fungi from the leaves of Pongamia pinnata (L.) Pierre (family Fabaceae), was collected from Karnala Bird Sanctuary near Panvel in Raigad District, Maharashtra, India in the month of March 2005, using a previously described method. ${ }^{6}$ Potato Dextrose Agar medium was used for isolation of fungi and maintenance of the culture for identification and fermentation purpose. The fungus was a sterile mycelium hence identified based on partial sequence analysis of the internal transcribed spacer region of rDNA using internal transcribed spacer-1 and internal transcribed spacer- 4 primers. ${ }^{7}$ A nucleotide to nucleotide BLAST ${ }^{8}$ query of the gene bank database (http://www.ncbi.nlm.nih.gov/BLAST) recovered AY601918.1 Phomopsis glabrae voucher SCHM 3622 as the closest match to the internal transcribed spacer rDNA of PM0509732 (99\%). Evolutionary analyses (Figure 1) were performed using MEGA6. ${ }^{9}$ Culture No. PM0509732 has been deposited with Microbial Type Culture Collection (MTCC), Institute of Microbial Technology, Chandigarh, India, and has been given the accession number MTCC5544.

\section{Large-scale production of the fungus}

A loop full of the well-grown culture from slant maintained on Potato dextrose agar was transferred to a $500 \mathrm{ml}$ conical flask with $100 \mathrm{ml}$ liquid medium containing soluble starch $1.5 \mathrm{~g}$; soyabean meal $1.5 \mathrm{~g}$; yeast extract $0.2 \mathrm{~g}$; corn steep liquor $0.1 \mathrm{~g}$; glucose $0.5 \mathrm{~g} ; \mathrm{CaCO}_{3} 0.2 \mathrm{~g} ; \mathrm{NaCl} 0.5 \mathrm{~g}$; glycerol $1.0 \mathrm{~g}$ in demineralized water at $\mathrm{pH}$ 5.5. This was grown on rotary shaker at 200 r.p.m. for $72 \mathrm{~h}$ at $28^{\circ} \mathrm{C}$ and was used as seed medium. The medium containing glucose, $30.00 \mathrm{~g} ; \mathrm{NaNO}_{3}, 3.00 \mathrm{~g} ; \mathrm{K}_{2} \mathrm{HPO}_{4}, 1.00 \mathrm{~g} ; \mathrm{KCl}, 0.50 \mathrm{~g} ; \mathrm{MgSO}_{4} \cdot 7 \mathrm{H}_{2} \mathrm{O}$, $0.50 \mathrm{~g} \mathrm{FeSO}_{4} \cdot 7 \mathrm{H}_{2} \mathrm{O}, 0.01 \mathrm{~g}$; demineralized water 11, was used for production. The $\mathrm{pH}$ of the medium was adjusted to 5.5 before sterilization. Hundred 


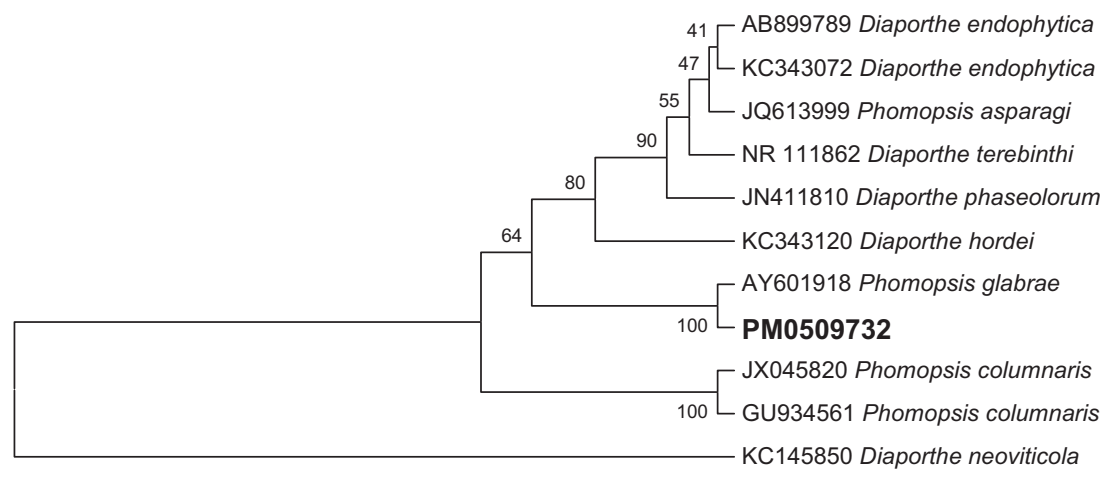

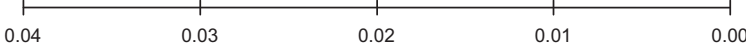

Figure 1 Phylogenetic analysis of the internal transcribed spacer region sequence obtained from culture PM0509732 in comparison with the nearest type strain sequences. The tree was constructed based on rRNA gene sequences (internal transcribed spacer region) using the Maximum Composite Likelihood Method.

$1000 \mathrm{ml}$ flasks containing $200 \mathrm{ml}$ of the above medium was inoculated with $1 \%$ of the seed culture and incubated on rotary shaker at 200 r.p.m. for $72 \mathrm{~h}$ at $28^{\circ} \mathrm{C}$.

\section{Purification of PM181110}

A fresh 201 fermentation batch of culture PM0509732 was processed, the whole fermented broth was filtered to separate $3 \mathrm{~kg}$ of biomass, which was extracted with acetone (101) via stirring. The organic solvent was separated from biomass through filtration and evaporated at $45^{\circ} \mathrm{C}$ under reduced pressure to obtain $2.5 \mathrm{~g}$ crude extract.

Crude extract was subjected to normal phase chromatography and eluted with different proportion of methanol in chloroform. Fractions were screened for anticancer activity and those found active were pooled to get $400 \mathrm{mg}$ semipure compound. The final purification was achieved by reverse phase preparative HPLC using acetonitrile and water as mobile phase in isocratic mode (4:6). The column used was Eurospher RP-18 $(250 \times 20 \mathrm{~mm}), 10 \mu \mathrm{m}$ with flow rate of $20 \mathrm{mlmin}^{-1}$. UV detection was observed at $220 \mathrm{~nm}$. PM181110 eluted at $11 \mathrm{~min}$ retention time. The eluate was concentrated at $45^{\circ} \mathrm{C}$ under reduced pressure to evaporate organic solvent, and residual water containing sample was freeze dried to get $100 \mathrm{mg}$ white amorphous powder (Table 1). PM181110 was characterized based on UV, IR, and various NMR experiments.

\section{In vitro assays}

Monolayer assay: cell lines. Forty human tumor cell lines derived from 15 different tumor histotypes, each represented by one-six cell lines were used for the study. Cell lines were established from cancer of the bladder (3), colon (4), head and neck (1), lung (6), breast (3), pancreas (3), prostate (4), ovary (2), kidney (3), liver (1), stomach (1) and the uteri body (1), as well as from melanoma (3), sarcoma (2) and pleuramesothelioma (3). Out of these 40 cell lines, 24 cell lines were established at Oncotest, from patient-derived tumor xenografts. The other 16 cell lines were either provided by the NCI (Bethesda; MD, USA) or were purchased from ATCC (Rockville, MD, USA) or DSMZ (Braunschweig, Germany). All cells were grown at $37^{\circ} \mathrm{C}$ in a humidified atmosphere with $5 \% \mathrm{CO}_{2}$ in Roswell Park Memorial Institute 1640 medium supplemented with $10 \%(\mathrm{v} / \mathrm{v})$ fetal calf serum and $0.1 \mathrm{mg} \mathrm{ml}^{-1}$ gentamicin (medium and all other components from PAA, Cölbe, Germany). Authenticity of all cell lines was proven by STR (short tandem repeat) analysis, a PCR based DNA-fingerprinting methodology.

Monolayer proliferation and cytotoxicity assay. A modified Propidium Iodide assay was used to assess the effect of the test compound on the growth of the human tumor cell lines. ${ }^{10}$ Cells were plated in 96-well flat-bottom microtiter plates at a cell density of 4000-20000 cells per well. After a $24 \mathrm{~h}$ recovery period to allow the cells to resume exponential growth,
Table 1 Physiochemical properties of PM181110

\begin{tabular}{|c|c|}
\hline Description & Details \\
\hline Appearance & White amorphous powder \\
\hline Solubility & $\begin{array}{l}\text { Soluble in pyridine, DMSO, chloroform } \\
\text { and methanol, insoluble in water }\end{array}$ \\
\hline HRESI-MS & $419.1640[\mathrm{M}+\mathrm{H}]^{+}$ \\
\hline UV $\lambda_{\max }$ & End absorption \\
\hline Molecular formula & $\mathrm{C}_{18} \mathrm{H}_{30} \mathrm{~N}_{2} \mathrm{O}_{5} \mathrm{~S}_{2}$ \\
\hline $\mathrm{IR} v_{\max }\left(\mathrm{cm}^{-1}\right)$ & $\begin{array}{l}3381,3346,2946,2861,1715,1671 \\
1645,1516,1435,1231,1016,796\end{array}$ \\
\hline $\begin{array}{l}\text { Analysis calculated } \\
\text { for } \mathrm{C}_{18} \mathrm{H}_{30} \mathrm{~N}_{2} \mathrm{O}_{5} \mathrm{~S}_{2}\end{array}$ & $C=51.6, H=7.1, N=6.69, O=19.1, S=15.3$ \\
\hline Found & $\mathrm{C}=51.5, \mathrm{H}=7.2, \mathrm{~N}=6.08, \mathrm{O}=18.4, \mathrm{~S}=16.7$ \\
\hline m.p. & $260-270^{\circ} \mathrm{C}$ \\
\hline
\end{tabular}

Abbreviation: DMSO, dimethyl sulfoxide.

the compound PM181110 was applied at 10 concentrations in half-log increments in triplicates and treatment continued for 4 days. After 4 days of treatment, cells were next washed with $200 \mu \mathrm{l}$ phosphate-buffered solution to remove dead cells, then $200 \mu \mathrm{l}$ of a solution containing $7 \mu \mathrm{g} \mathrm{ml}^{-1}$ propidium iodide and $0.1 \%(\mathrm{v} / \mathrm{v})$ Triton $\mathrm{X}-100$ were added to the wells. After an incubation period of $1-2 \mathrm{~h}$ at room temperature, fluorescence was measured using the Cytofluor 4000 microplate reader (Millipore, Schwalbach, Germany) (excitation $\lambda=530 \mathrm{~nm}$, emission $\lambda=620 \mathrm{~nm}$ ) to quantify the amount of attached viable cells. Pharmacological effects on cell proliferation and survival were expressed as Test/Control $\times 100(\% \mathrm{~T} / \mathrm{C})$ values. On the basis of the $\mathrm{T} / \mathrm{C}$ values, relative $\mathrm{IC}_{50}$ values were determined by non-linear regression ( $\log [$ conc. of inhibitor] versus response $(\% \mathrm{~T} / \mathrm{C})$ ) using the GraphPad Prism analysis software (Prism 5 for Windows, version 5.01, GraphPad Software, CA, USA). For calculation of mean $\mathrm{IC}_{50}$ values over the 40 cell lines as tested, the geometric mean was selected.

For mode-of-action analysis, a Compare Analysis was performed. The individual $\mathrm{IC}_{50}$ values of the test compound as obtained in Oncotest's 40 cell line panel in the monolayer assay were correlated by a Spearman rank test to the corresponding $\mathrm{IC}_{50}$ values for 94 standard agents as determined for these 40 cell lines. These standard agents represent the main MoAs of approved and experimental anticancer drugs. Similarities between the activity pattern of a test compound and those of standard drugs are expressed quantitatively as Spearman correlation coefficients. High correlations $(\rho>0.6, P<0.05)$ between the activity patterns of two compounds are indicative of a similar MoA. 
Clonogenic assay. Antitumor efficacy on clonogenicity of tumor cells was investigated in a clonogenic assay. Tumor xenografts were derived from patient tumors engrafted as a subcutaneously growing tumor in NMRI nu/nu mice obtained from Oncotest's breeding facility. ${ }^{11,12}$ Details of the test procedure have been described earlier. ${ }^{13}$ Briefly, solid human tumor xenografts were removed from mice under sterile conditions, mechanically disaggregated and subsequently incubated with an enzyme cocktail consisting of collagenase type IV $\left(41 \mathrm{U} \mathrm{ml}^{-1}\right)$, DNase I $\left(125 \mathrm{U} \mathrm{ml}^{-1}\right)$, hyaluronidase type III $\left(100 \mathrm{U} \mathrm{ml}^{-1}\right)$ and dispase II $\left(1.0 \mathrm{U} \mathrm{ml}^{-1}\right)$ in Roswell Park Memorial Institute 1640 Medium at $37^{\circ} \mathrm{C}$ for $45 \mathrm{~min}$. Cells were passed through sieves of $200 \mu \mathrm{m}$ and $50 \mu \mathrm{m}$ mesh size and washed twice with sterile phosphate-buffered solution buffer. The percentage of viable cells was determined in a Neubauer hemocytometer using trypan blue exclusion. The bottom layer consisted of $0.2 \mathrm{ml}$ per well Iscove's Modified Dulbecco's Medium (Life Technologies, Darmstadt, Germany), supplemented with $20 \% \quad(\mathrm{v} / \mathrm{v})$ fetal calf serum (Sigma, Taufkirchen, Germany), $0.01 \% \quad(w / v)$ gentamicin (Life Technologies, Darmstadt, Germany) and $0.75 \%(\mathrm{w} / \mathrm{v})$ agar (BD Biosciences, Heidelberg, Germany). Cells $\left(1.5 \times 10^{4}\right.$ to $\left.4 \times 10^{4}\right)$ were added to $0.2 \mathrm{ml}$ of the same culture medium supplemented with $0.4 \%(\mathrm{w} / \mathrm{v})$ agar and plated in $24-$ multiwell dishes onto the bottom layer. The test compounds were applied by continuous exposure (drug overlay) in $0.2 \mathrm{ml}$ of culture medium. Every dish included six untreated control wells and drug-treated groups in triplicate at six concentrations. Cultures were incubated at $37^{\circ} \mathrm{C}$ and $7.5 \% \mathrm{CO}_{2}$ in a humidified atmosphere for 7-20 days and monitored closely for colony growth using an inverted microscope. Within this period, in vitro tumor growth led to the formation of colonies with a diameter of $>50 \mu \mathrm{m}$. At the time of maximum colony formation, counts were performed with an automatic image analysis system (Bioreader 5000W $\alpha$, Biosys, Karben, Germany). Twenty-four hours before evaluation, vital colonies were stained with a sterile aqueous solution of 2-(4-iodophenyl)-3-(4-nitrophenyl)-5-phenyltetrazolium chloride $\left(1 \mathrm{mg} \mathrm{ml}^{-1}, 100 \mu \mathrm{l}\right.$ per well).

For testing hematopoietic stem cells, samples of human umbilical cord blood were diluted two-threefold with phosphate-buffered solution containing $0.1 \%(\mathrm{w} / \mathrm{v})$ bovine serum abumin. Peripheral blood mononuclear cells were enriched from the respective samples by Ficoll Paque density gradient centrifugation and washed twice with phosphate-buffered solution containing $0.1 \%(\mathrm{w} / \mathrm{v})$ bovine serum albumin. The resulting cell suspension was stored in aliquots in freezing medium at $-80^{\circ} \mathrm{C}$. Aliquots were thawed for testing as appropriate. The colony forming test was performed using 24-well plates and HSC-CFU (Miltenyi Biotec, Bergisch Gladbach, Germany) as culture medium. 25000 cells ml ${ }^{-1}$ of the above mentioned preparation were seeded in a final volume of $500 \mu \mathrm{l}$ per well. Solutions of the test compounds were added directly to the medium. Every dish included six untreated control wells and drugtreated groups in triplicate at five concentrations. Three wells of the test plate were filled with $1 \mathrm{ml}$ of sterile water to ensure that maximum humidity was attained during the subsequent incubation period. Cultures were incubated at $37^{\circ} \mathrm{C}$ and $7.5 \% \mathrm{CO}_{2}$ in a humidified atmosphere for 12 days. Colony growth was evaluated using an inverted microscope.

Xenograft models and in vivo efficacy testing. The bladder cancer xenograft BXF 1218 was established at Oncotest $\mathrm{GmbH}$ from primary patient material after the informed consent of the patient. Tumor pieces were implanted subcutaneously and four mice per group were randomized after reaching tumor volumes of about $50-250 \mathrm{~mm}^{3}$. Mice were treated with $1.0,0.5$ and $0.25 \mathrm{mg} \mathrm{kg}^{-1}$ PM181110 i.p. on days 0 (randomization), 4 and 8 and the vehicle control was 30\% dimethyl sulfoxide/70\% (10\% cremophor EL/90\% aai). Tumor sizes were measured twice weekly until study day 11 . The treatment versus control (T/C (\%)) values were calculated by using the median relative tumor volumes. Optimal T/C values were used to assess PM181110 response. All studies were performed in agreement with animal welfare acts in Germany.

\section{RESULTS AND DISCUSSION}

The mycelium of the fungus Phomopsis glabrae was extracted with acetone. The resulting acetone extract was dried and chromatographed on silica gel followed by preparative HPLC to yield PM181110 (Figure 2). The compound PM181110 was characterized by spectroscopic data analysis (Table 2) (UV, ${ }^{1} \mathrm{H}$ NMR, ${ }^{13} \mathrm{CNMR}$ and LC/MS, Supplementary Figures S1-S5).

${ }^{13} \mathrm{C}$ NMR indicated amide functional groups and were assigned to $\delta 174.1$ and 173.9. Additional signal at 169.4 was attributed to a lactone group. Signals 74.5 and 70.3 were attributed to two $\mathrm{CH}-\mathrm{O}$ chemical bond in the compound. Two carbon signals at 52.0 and 51.2 were assigned for two $\mathrm{CH}-\mathrm{N}$ linkages. Remaining carbons were assigned for methylene and terminal methyl groups. The DEPT-135 indicated four $\mathrm{CH}$, ten $\mathrm{CH}_{2}$, one $\mathrm{CH}_{3}$ spin system. The methyl group was a terminal one having a triplet in ${ }^{1} \mathrm{H}$ NMR. The two $\mathrm{CH}_{2}$ protons located at disulfide bond were found to have COSY correlation with their adjacent protons. COSY correlations were established between $\delta$ 4.04 and $1.64,1.41$, indicated the presence of $\mathrm{C}-\mathrm{OH}$ moiety adjacent to methylene group. ${ }^{13} \mathrm{C}$ NMR data showed sets of carbon signals due to tautomeric equilibrium of PM181110, which is also reported for FE399. ${ }^{1} \mathrm{H}$ NMR data indicated two hetero atoms attached proton

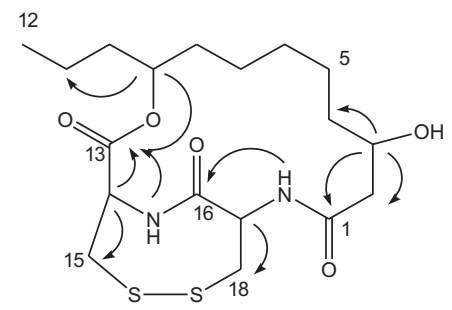

PM 181110<smiles>CCCC1CCCCCCCC(=O)NCCSSCC1C(=O)OCC</smiles>

FE399
Figure 2 Structure with HMBC and COSY correlations of PM181110 and structure of FE 399.

Table $2{ }^{13} \mathrm{C}$ NMR (DMSO-d6, $75 \mathrm{MHz}$ ) and ${ }^{1} \mathrm{H}$ NMR ( DMSO-d6, $500 \mathrm{MHz}$ ) data of PM181110 and ${ }^{13} \mathrm{C}$ NMR of FE399 (DMSO-d6, $100 \mathrm{MHz}$ )

\begin{tabular}{|c|c|c|c|}
\hline & $\delta C$ (p.p.m.) & $\delta C($ p.p.m.) & \\
\hline C number & PM181110 & FE399 & $\delta H$ (p.p.m.) PM181110 \\
\hline 1 & 173.9 & 173.1 & - \\
\hline 2 & 35.6 & 34.9 & $1.41,1.64(2 \mathrm{H}, \mathrm{d})$ \\
\hline 3 & 70.3 & 24.8 & $4.04(1 \mathrm{H}, \mathrm{m})$ \\
\hline 4 & 34.3 & 26.6 & $1.64(2 \mathrm{H}, \mathrm{m})$ \\
\hline 5 & 27.9 & 26.6 & $1,21(2 \mathrm{H}, \mathrm{m})$ \\
\hline 6 & 26.7 & 26.9 & $1.24(2 \mathrm{H}, \mathrm{m})$ \\
\hline 7 & 22.0 & 21.6 & $1.26(2 \mathrm{H}, \mathrm{m})$ \\
\hline 8 & 32.9 & 32.3 & $1.52(2 \mathrm{H}, \mathrm{m})$ \\
\hline 9 & 74.5 & 74.2 & $4.98(1 \mathrm{H}, \mathrm{m})$ \\
\hline 10 & 36.2 & 36.0 & $1.41(2 \mathrm{H}, \mathrm{m})$ \\
\hline 11 & 18.3 & 18.3 & $1.28(2 \mathrm{H}, \mathrm{m})$ \\
\hline 12 & 13.7 & 13.7 & $0.85(3 \mathrm{H}, \mathrm{t})$ \\
\hline 13 & 169.4 & 170.3 & - \\
\hline 14 & 52.0 & 53.5 & $4.86(1 \mathrm{H}, \mathrm{m})$ \\
\hline 15 & 42.7 & 44.1 & $3.62(1 \mathrm{H}, \mathrm{m}), 3.29(1 \mathrm{H}, \mathrm{d}, J=15 \mathrm{~Hz})$ \\
\hline 16 & 174.1 & 174.8 & - \\
\hline 17 & 51.2 & 52.6 & $3.96(1 \mathrm{H}, \mathrm{m})$ \\
\hline 18 & 43.2 & 47.4 & $3.40(1 \mathrm{H}, \mathrm{m}), 3.10(1 \mathrm{H}, \mathrm{d}, J=15 \mathrm{~Hz})$ \\
\hline $\mathrm{NH}$ & - & - & $8.16(1 \mathrm{H}, \mathrm{brs})$ \\
\hline $\mathrm{NH}$ & - & - & $8.87(1 \mathrm{H}, \mathrm{brs})$ \\
\hline
\end{tabular}

Abbreviation: DMSO, dimethyl sulfoxide.

${ }^{1} \mathrm{H}$ NMR of FE399 (Pyridine d-5, $\left.600 \mathrm{MHz}\right) \delta 9.55(1 \mathrm{H}, \mathrm{s}), 7.97(1 \mathrm{H}, \mathrm{d}), 5.84(1 \mathrm{H}, \mathrm{t}), 5.19$ $(1 \mathrm{H}, \mathrm{brs}), 4.88(1 \mathrm{H}, \mathrm{s}), 4.04(2 \mathrm{H}, \mathrm{m}), 3.65(1 \mathrm{H}, \mathrm{d}), 3.47(1 \mathrm{H} . \mathrm{d}), 2.56(1 \mathrm{H}, \mathrm{t}), 2.37(1 \mathrm{H}, \mathrm{t}), 2.12$ $(1 \mathrm{H}, \mathrm{m}), 1.11-1.51,0.8(1 \mathrm{H}, \mathrm{t})$ 
at 8.87 and 8.16 , which were confirmed by $\mathrm{D}_{2} \mathrm{O}$ exchange. Two proton signals at 4.98 and 4.04 were attributed to $\mathrm{CH}-\mathrm{O}$ functionalities. Important HBMC correlations have been shown in the structure of PM181110. The structure was well supported by NMR experiments like HSQC, HMBC and COSY spectra. The different

Table 3 In vitro antitumor activity of PM181110 in a panel of 40 human tumor cell lines

\begin{tabular}{|c|c|c|c|}
\hline Sr No. & Cell line & Histotype & $I C_{50}(\mu \mathrm{M}$ \\
\hline 1 & BXF 1218L & Bladder & 0.046 \\
\hline 2 & BXF 1352L & Bladder & 0.103 \\
\hline 3 & BXF T 24 & Bladder & 0.05 \\
\hline 4 & CXF 269L & Colon & 0.055 \\
\hline 5 & CXF HCT 116 & Colon & 0.048 \\
\hline 6 & CXF HT 29 & Colon & 0.137 \\
\hline 7 & CXF RKO & Colon & 0.074 \\
\hline 8 & GXF $251 \mathrm{~L}$ & Gastric & 0.093 \\
\hline 9 & HNXF CAL 27 & Head and neck & 0.039 \\
\hline 10 & LIXF 575L & Liver & 0.295 \\
\hline 11 & LXFA 289L & Lung & 0.041 \\
\hline 12 & LXFA 526L & Lung & 0.021 \\
\hline 13 & LXFA 629L & Lung & 0.04 \\
\hline 14 & LXFL 1121L & Lung & 0.047 \\
\hline 15 & LXFL 529L & Lung & 0.05 \\
\hline 16 & LXFL H 460 & Lung & 0.146 \\
\hline 17 & MAXF 401NL & Mammary & 0.064 \\
\hline 18 & MAXF MCF 7 & Mammary & 0.276 \\
\hline 19 & MAXF MDA 231 & Mammary & 0.09 \\
\hline 20 & MEXF 1341L & Melanoma & 0.102 \\
\hline 21 & MEXF 276L & Melanoma & 0.09 \\
\hline 22 & MEXF 462NL & Melanoma & 0.149 \\
\hline 23 & OVXF 899L & Ovarian & 0.301 \\
\hline 24 & OVXF OVCAR3 & Ovarian & 0.195 \\
\hline 25 & PAXF 1657L & Pancreas & 0.039 \\
\hline 26 & PAXF 546L & Pancreas & 0.016 \\
\hline 27 & PAXF PANC 1 & Pancreas & 0.059 \\
\hline 28 & PRXF 22RV1 & Prostate & 0.159 \\
\hline 29 & PRXF DU 145 & Prostate & 0.052 \\
\hline 30 & PRXF LNCAP & Prostate & 0.122 \\
\hline 31 & PRXF PC3M & Prostate & 0.047 \\
\hline 32 & PXF 1118L & Pleuramesothelioma & 0.054 \\
\hline 33 & PXF 1752L & Pleuramesothelioma & 0.187 \\
\hline 34 & PXF 698L & Pleuramesothelioma & 0.178 \\
\hline 35 & RXF 1781L & Renal & 0.26 \\
\hline 36 & RXF 393NL & Renal & 0.323 \\
\hline 37 & RXF 486L & Renal & 0.159 \\
\hline 38 & SXF SAOS2 & Sarcoma & 0.185 \\
\hline 39 & SXF TE671 & Sarcoma & 0.082 \\
\hline \multirow[t]{2}{*}{40} & UXF 1138L & Uterus & 0.126 \\
\hline & Mean & & 0.089 \\
\hline
\end{tabular}

conformers of PM181110 could be seen depending on solvent and temperature. This observation was also established by two sets of carbon signals. The isolated compound has also been compared with similar class of compound antitumour antibiotic FE399. ${ }^{14}$

\section{In vitro antitumor activity of PM181110 in a panel of 40 human tumor cell lines}

PM181110 was investigated in a panel of 40 human tumor cell lines, comprising 15 different tumor histotypes, each represented one to six cell lines. PM181110 showed concentration-dependent activity in all cell lines as tested, that is, cell lines derived from bladder, colon, gastric, head and neck, liver, lung (non-small-cell lung carcinoma), mammary, ovarian, pancreatic, prostate, renal and uterus cancer, as well as melanoma, pleuramesothelioma and sarcoma (Table 3). The overall very strong antitumor potency was evident from a mean $\mathrm{IC}_{50}$ value of $0.089 \mu \mathrm{M}$ with individual $\mathrm{IC}_{50}$ values in the range from $16 \mathrm{~nm}$ to $0.323 \mu \mathrm{M}$ As shown in Table 4, above-average sensitivity was particularly found in cell lines derived from bladder (two out of three tested bladder cancer cell lines with individual $\mathrm{IC}_{50}<$ mean $\left.\mathrm{IC}_{50}\right)$, colon (3/4), lung (5/6) and pancreatic cancer (3/3). Mainly, the activity towards the $5 / 6$ cell lines derived from lung carcinoma (individual $\mathrm{IC}_{50} \leqslant 0.05 \mu \mathrm{M}$ ) and towards the $3 / 3$ pancreatic tumor cell lines (individual $\mathrm{IC}_{50}<0.06 \mu \mathrm{M}$ ) is to be highlighted. The most sensitive cell lines towards PM181110 were found to be the pancreatic cancer cell line PAXF 546L $\left(\mathrm{IC}_{50}=0.016 \mu \mathrm{M}\right)$ and the lung cancer cell line LXFA 526L $\left(\mathrm{IC}_{50}=0.021 \mu \mathrm{M}\right)$. Compare Analysis revealed no significant correlations to any of the reference compounds (Spearman correlation coefficient $\rho<0.4)$ indicated that the mode-of-action of PM181110 was not represented by the reference compounds used for Compare Analysis.

\section{Ex vivo antitumor efficacy of PM18110 in a panel of 24 human tumor xenografts}

Inhibition of clonogenicity of tumor cells was evaluated in additional tumor models using a clonogenic assay. The antiproliferative activity of PM181110 was evaluated in cell suspensions prepared from 24 human tumor xenografts of 13 different histotypes, which were cultured as solid tumors in serial passage on immune deficient nude mice. In addition, PM181110 was tested in two preparations of hematopoietic stem cells as a model system for non-malignant tissue. $\mathrm{IC}_{50}$ values in the clonogenic assays using tumor cell suspensions ranged from $0.03 \mu \mathrm{M}$ to $0.422 \mu \mathrm{M}$ (geometric mean $\mathrm{IC}_{50}=0.245 \mu \mathrm{M}$ ). Colony formation of hematopoietic stem cells derived from cord blood was inhibited by with $\mathrm{IC}_{50}$ values of $0.26 \mu \mathrm{M}$ and $0.746 \mu \mathrm{M}$, respectively (Table 5). The bladder cancer BXF $1218\left(\mathrm{IC}_{50}=0.03 \mu \mathrm{M}\right)$ was identified to be the most sensitive tumor model.

In vivo antitumor efficacy of PM18110 in human tumor xenografts Four mice per group were randomized when tumor volume of the bladder cancer xenografts BXF 1218 was around $50-250 \mathrm{~mm}^{3}$. Vehicle-treated tumors grew fast (doubling time $=1.6$ days) and

Table 4 In vitro antitumor activity of PM181110 towards cell lines derived from selected tumor histotypes

\begin{tabular}{|c|c|c|c|c|c|c|c|c|c|}
\hline \multicolumn{10}{|c|}{ Above average activity towards selected tumor histotypes ${ }^{a}$} \\
\hline Mean $I C_{50}(\mu m)$ & Bladder & Colon & Lung & Breast & Melanoma & Pancreas & Prostate & Pleurameso & Kidney \\
\hline 0.089 & $2 / 3$ & $3 / 4$ & $5 / 6$ & $1 / 3$ & $0 / 3$ & $3 / 3$ & $2 / 4$ & $1 / 3$ & $0 / 3$ \\
\hline
\end{tabular}

aNumber of cell lines among the respective histotype with individual $\mathrm{IC}_{50}<$ mean $\mathrm{IC}_{50}$. 
Table 5 Ex vivo antitumor efficacy of PM181110 in a panel of 24 human tumor xenografts using a clonogenic assay

\begin{tabular}{|c|c|c|c|}
\hline No. & Tumor model & Histotype & $I C_{50}(\mu \mathrm{M})$ \\
\hline 1 & AHS NSB020 & Non-malignant & 0.260 \\
\hline 2 & AHS NSB022 & Non-malignant & 0.746 \\
\hline 3 & BXF 1218 & Bladder & 0.030 \\
\hline 4 & CXF 1103 & Colon & 0.294 \\
\hline 5 & CXF 1729 & Colon & 0.235 \\
\hline 6 & CXF 243 & Colon & 0.282 \\
\hline 7 & GXF 1172 & Stomach & 0.203 \\
\hline 8 & GXF 97 & Stomach & 0.188 \\
\hline 9 & HNXF 536 & Head and neck & 0.330 \\
\hline 10 & LXFA 526 & Lung & 0.269 \\
\hline 11 & LXFA 629 & Lung & 0.376 \\
\hline 12 & LXFE 1422 & Lung & 0.238 \\
\hline 13 & LXFL 430 & Lung & 0.169 \\
\hline 14 & LXFL 529 & Lung & 0.203 \\
\hline 15 & MAXF 1322 & Breast & 0.422 \\
\hline 16 & MAXF 401 & Breast & 0.306 \\
\hline 17 & MEXF 462 & Melanoma & 0.267 \\
\hline 18 & MEXF 989 & Melanoma & 0.206 \\
\hline 19 & OVXF 1353 & Ovary & 0.212 \\
\hline 20 & OVXF 899 & Ovary & 0.330 \\
\hline 21 & PAXF 546 & Pancreas & 0.194 \\
\hline 22 & PRXF PC3M & Prostate & 0.226 \\
\hline 23 & PXF 1752 & Mesothelioma & 0.288 \\
\hline 24 & RXF 1220 & Kidney & 0.254 \\
\hline 25 & RXF 631 & Kidney & 0.333 \\
\hline \multirow[t]{2}{*}{26} & SXF 1301 & Sarcoma & 0.217 \\
\hline & Mean & & 0.245 \\
\hline
\end{tabular}

had to be killed after 11 days due to tumor burden of around $1700 \mathrm{~mm}^{3}$. PM181110 was given i.p. at dose levels of 1.0, 0.5 and $0.25 \mathrm{mg} \mathrm{kg}^{-1}$ on days 0,4 and 8 . At a dose of $1.0 \mathrm{mg} \mathrm{kg}^{-1}$, a test/ control value of $31 \%$ was achieved with $11 \%$ body weight loss. The other two doses were well tolerated but showed no antitumor activity.
It is expected that optimization of formulation and dose regimen would help to improve the efficacy of the molecule.

\section{ACKNOWLEDGEMENTS}

We are thankful to the analytical discovery group at Piramal Life Sciences for recording spectral data. We are also thankful to Dr H. Sivaramakrishnan, Dr Arun Balakrishnan, and Dr Rajiv Sharma, Piramal Enterprises Ltd. Mumbai for all their help and support.

1 Puri, S. C., Verma, V., Amna, T., Qazi, G. N. \& Spiteller, M. An endophytic fungus from Nothapodytes foetida that produces camptothecin. J. Nat. Prod. 68, 1717-1719 (2005).

2 Gueritte, F. \& Fahy, J. In The Vinca Alkaloids (eds Cragg, G. M., Kingston, D. G. I. \& Newman, D. J.) 123-136 (Anticancer Agents from Natural Products Taylor and Francis, Boca Raton, 2005).

3 Ding, G. et al. Chaetoglobosin U, a cytochalasan alkaloid from endophytic Chaetomium globosum IFB-E019. J. Nat. Prod. 69, 302-304 (2006).

4 Stierle, A. A. \& Stierle, D. B. in: Studies in Natural Products Chemistry (ed Atta-ur-Rahman) Vol. 24 (Part E), 933-977 (Elsevier, 2000).

5 Kharwar, R. N., Mishra, A., Gond, S. K., Stierle, A. \& Stierle, D. Anticancer compounds derived from fungal endophytes: their importance and future challenges. Nat. Prod. Rep. 28, 1208-1228 (2011).

6 Suryanarayanan, T. S., Kumaresan, V. \& Johnson, J. A. Foliar fungal endophytes from two species of the mangrove Rhizophora. Can. J. Microbiol. 44, 1003-1006 (1998).

7 White, T. J., Bruns, T., Lee, S. \& Taylor, J. W. In: PCR Protocols: a Guide to Methods and Applications (Eds Innis, M A et al. ) 315-322 (Academic Press, Inc, New York, NY, USA, 1990).

8 Altschul, S. F., Gish, W., Miller, W., Myers, E. W. \& Lipman, D. J. Basic local alignment search tool. J. Mol. Biol. 215, 403-410 (1990).

9 Tamura, K., Stecher, G., Peterson, D., Filipski, A. \& Kumar, S. MEGA6: Molecular Evolutionary Genetics Analysis version 6.0. Mol. Biol. Evol. 30, 2725-2729 (2013).

10 Dengler, W.A., Schulte, J., Berger, D.P., Mertelsmann, R. \& Fiebig, H.H. Development of a propidium iodide fluorescence assay for proliferation and cytotoxicity assays. Anticancer Drugs. 6, 522-532 (1995).

11 Fiebig, H. H., Berger, D. P., Dengler, W. A., Wallbrecher, E. \& Winterhalter, B. R. in Immunodeficient Mice in Oncology. Contrib. Oncol. (eds Fiebig, H. H. \& Berger, D. P.) 321-351 (Karger, Basel, 1992).

12 Fiebig, H. H., Dengler, W. A. \& Roth, T. In Relevance of Tumor Models for Anticancer Drug Development. Contrib oncol. (eds Fiebig, H. H. \& Burger, A. M.) 29-50 (Karger, Basel, 1999).

13 Fiebig, H. H., Maier, A. \& Burger, A. M. Clonogenic assay with established human tumour xenografts: correlation of in vitro to in vivo activity as a basis for anticancer drug discovery. Eur. J. Cancer 40, 802-820 (2004).

14 Oobayashi, Y. et al. Group of antitumor compounds and method for producing the same. US Patent 005843755 (1998).

Supplementary Information accompanies the paper on The Journal of Antibiotics website (http://www.nature.com/ja) 